practices of certain members of the Bear gens of the Fox Indians of Oklahoma, to which reference is made in a recent publication of the Bureau of American Ethnology ("Notes on the Fox Wâpanowiweni": by Truman Michelson, Bull. 105). The bear, it may be mentioned, in parenthesis, is considered among the Fox to be the most dread form of witch. An Indian informant, who, significantly enough, wished to remain anonymous, stated that he himself had seen certain members of the gens remove stones or feathers from a box without touching it or its contents. Balls of fire were produced, and skins of snakes and cat and otter skins came alive and spoke. In the matter of the closed box the identity with the West African claim is noteworthy. Other performances resembled those of the spiritualistic medium. Stones ran round in a circle. The witches successfully called on the Wâpanowi birds (spirits) to come; they handled redhot coals without suffering harm, and plunging their bare arms into boiling water, took out meat with impunity. This last feat has been recorded among a number of the American Indian peoples.

As attempt by Fox Indian witches to injure or kill an individual who sought to ward off their attempts on his sister, was frustrated by giving them a feast at which the food provided by their host and intended victim was the head of a witch who had been captured by burning cedar leaves. When the witches invited him to a ceremonial feast, they were unable to take the meat from boiling water with bare arms, but he succeeded; they handled red-hot coals and he did the same. Then they became afraid. The next day the ceremony ended without any special event. Presumably the intended victims had evaded the danger. It will be remembered that it was claimed for the notorious medium Home that he had transferred his immunity to red-hot coal to someone else for a brief period; but with the Fox the transfer would seem to have been involuntary, although, it is said, the intended victim had been told previously "how to excel in shamanistic tricks". It has been questioned whether medicine men and shamans have the hyp. notic powers sometimes claimed for them-rather, it is to be feared, as the last resource of an exhausted attempt at explanation; but it may be noted that it is said of one Fox witch that "when he was looked at steadily by anyone, the other became sleepy,... and ... when [anyone] did not take his gaze from him, he fell asleep".

\section{Anniversary of the Science Museum}

ThE South Kensington Museum was first opened to the public on July 1, 1857, and the seventy-fifth anniversary is being marked at the Science Museum by a special exhibition of technical apparatus, etc., which will remain on view until October. The wonderful progress which has been made in all branches of science and technology is shown by exhibiting examples which were in use during the decade 1850-60 alongside the corresponding types which are in use to-day, and emphasising the contrast in the descriptive notices. Air, land, and water transport are represented, and the remarkable ad- vances which have been made in mathematical instruments, lighting equipment, telegraphy, typewriters, sewing machines, marine engines, pumping machinery, stationary engines, metallurgy, and other fields are shown by actual examples or by scale models. The discovery of the first artificial dye by W. H. Perkin in 1856 provides a very striking example of the progress made in industrial chemistry when the products of that date are compared with those of the dyeing industry of to-day. Besides a type exhibit placed among the others of the exhibition, a much larger and more representative display of modern dyes and dyed materials has been arranged in Gallery 66 on the top floor of the Museum. A series of plans shows how the Gore Estate has been developed by the Commissioners of the Great Exhibition of 1851 during the past eighty years, from the original group of green fields to the great intellectual centre which it is to-day. Since the South Kensington Museum, now represented by the Victoria and Albert Museum and the Science Museum, was established on the initiative of the Prince Consort, the attendance records total more than seventy-eight million, and about two million visits annually are still recorded.

\section{National Prosperity and Control of Production}

IN a pamphlet entitled "The Next Step", Capt. Harold Macmillan, M.P., advances the proposition that prosperity is conditioned by equilibrium in production. If the forces of production are properly distributed in the production of consumptive goods, and if the rate of saving is equalled by the rate of capital investment, then the total products will exchange against each other and prices and employment will be stable. This is the ideal production balance, but the difficulty of maintaining it becomes evident when it is visualised as a continuous rather than a static balance. Fluctuations are inevitable, and the balance may be utpset by financial, political, or industrial forces. Capt. Macmillan therefore argues that it is necessary to create an organisational structure which will guide the flow of capital investment, secure the production of commodities in the quantities which scientific market study direets, and maintain stability of prices as the governing principle in credit policy. To attain these ends, he advocates the following programme: (1) a seientific system of selective protection of our home market ; $(2)$ the establishment of representative national councils for each industry, to co-ordinate purchasing, production, marketing, and research; (3) the creation of an investment and development board representing the Government, industry, and finance, to direct investment into the correct channels, to influence credit policy, and to direct the efforts of the councils of industry so as to achieve a new internal production balance in relation to the most scientific estimation of market require. ments ; (4) reflation to the 1928 price level.

Capt. Harold Macmillan also advocates the "planning of stability". He argues that Britain has inherited a population and economic structure adjusted to a stage of world development which is past. Adjustments must now be made which ought to have

$$
\text { No. } 3270 \text {, VoL. 130] }
$$

